\title{
RESPONSIVE FAÇADES DESIGN USING NANOMATERIALS FOR OPTIMIZING BUILDINGS' ENERGY PERFORMANCE
}

\author{
HEBA NABIL ABDEL AZIZ \& MOHAMED IBRAHIM ABDELALL \\ Architecture Department, Faculty of Engineering, Alexandria University, Egypt
}

\begin{abstract}
According to the International Energy Agency (IEA) buildings and construction sector globally is showing an increase in both emissions and energy use, limited progress on new and existing policies, and a further slowdown in energy-efficiency investment growth. In the meantime, $40-60 \%$ of all energy used in buildings is affected by the design and construction of building façades therefore, considering sustainable strategies for energy efficiency of building façades are very important. Responsive façades can improve buildings' energy performance as they create an adaptive environmental filter around the buildings with the ability to interact with the outdoor conditions. New building façades materials and technologies are needed to encourage construction towards nearly zero-energy buildings. For this reason, the construction industry recently started combined the use of nanomaterial with conventional building material. These adaptive nanomaterials can be integrated into buildings' responsive façades, based on the specific material properties that can be modulated. To vary their solar properties (transmission, absorption and reflection coefficients) as well as their heat transfer (thermal conductivity). This research presents a comprehensive overview of responsive façades detention and classification through novel information focused on the systems which use active nanomaterials to enhance buildings' energy efficiency.
\end{abstract}

Keywords: adaptive nanomaterials, energy efficiency, energy performance, nanomaterials, phase change materials, responsive façades, shape memory materials.

\section{INTRODUCTION}

During the last decade the construction of energy efficient buildings centred around two strategies: firstly, the installation of highly efficient energy recovery systems and secondly, the use of passive design solutions to improve the efficiency of building façades. For example, optimizing buildings shape or improving insulation materials for façades and windows, however, this static design concept cannot be sufficient to achieve environmental sustainability targets [1].

This is based on the fact that the limitation of static façades to how much energy savings can be achieved as they are incapable of interacting with the outdoor conditions which would benefit the indoor environment consistently, as well as give building users the ability to modify the building façades to meet their needs. With seasonal variability, and changing of weather patterns, static façades cannot provide consistent climate control [1].

Like the skin is to the human body, building façades have the responsibility to regulate internal physical conditions. Thus, "responsive building façades" could solve problems faced by static façades by supplying the ability to play more than one role at a time according to outdoor climate conditions. Such as, allowing solar heat during certain times but restricting it at other times. Ultimately, shifting between functions in adaptation to different conditions allows façades to decrease energy consumption and improve the efficiency of building energy [2].

A noticeable change on architectural skins appeared during the second half of the last century the building envelopes role has evolved from protection only to energy storage, and 
generation according to need through many improvements in terms of materials, system designs, and energy efficiency simulations [2].

\section{RESPONSIVE FAÇADES}

Responsive façades can effectively respond to the changes in the interior and exterior environment to achieve or improve the envelopes' functional requirements in terms of thermal comfort, air and water vapour movement, solar radiation, strength and stability. Therefore, multi-functional responsive façades should be able to respond repeatedly and reversibly over time to changes in performance requirements and changing boundary conditions. In other words, responsive façades would be able to provide controllable insulation and thermal mass, radiant heat exchange, ventilation, energy harvesting, daylighting, solar shading or humidity control [3].

\subsection{Classification of responsive building façades systems}

Responsive systems are primarily classified into three different categories shown in Fig. 1, according to responsivity type [4], [5].

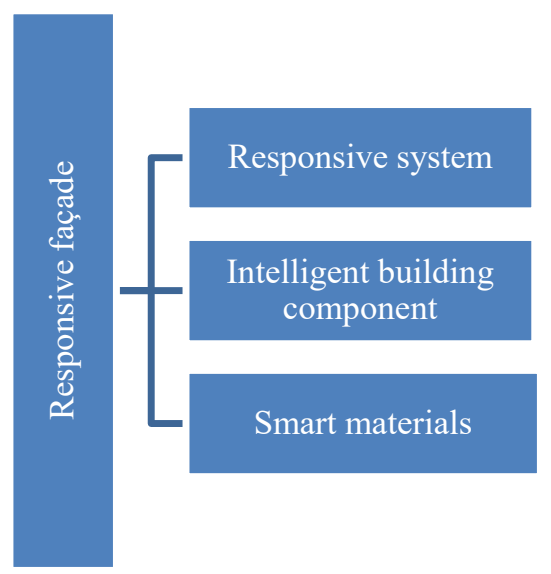

Figure 1: Responsive façade classification. (Source: [4], [5] edited by author.)

\subsubsection{Responsive system}

The term "responsive" in building façades describe "the interact, and response between natural, and artificial system using computational algorithms to ensure the building system's ability to self-adapt and learn over time (Table 1). Systems equipped with sensors, processing units, and actuators that can be programmed and could answer to real-time weather conditions were incorporated into the envelope [6]. They are based on data acquisition systems (DAS) of a closed loop protocol, based on an integrated system where the stimuli are sensed, and their processing is used as a control device [7].

As a result, responsive building skins not only incorporate methods for user sensing and response, but are also devoted to informing the building and its occupants. Data is presented to the building's users through an interface system, called ALIS (adaptive living interface system). It provided real-time energy and resource use feedback in both numerical 
Table 1: Responsive façade system and mechanisms. (Source: [6] edited by author.)

\begin{tabular}{|l|l|l|}
\hline Response input & Mechanical elements & Smart Material \\
\hline $\begin{array}{l}\text { Exterior climate } \\
\text { Sun-wind-moisture } \\
\text { pollution }\end{array}$ & $\begin{array}{l}\text { Movable sunshades - louvers } \\
- \text { panels }\end{array}$ & $\begin{array}{l}\text { State change - energy } \\
\text { change }\end{array}$ \\
\hline $\begin{array}{l}\text { Interior climate } \\
\text { Temperature - humidity - } \\
\text { CO2- VOCs }\end{array}$ & $\begin{array}{l}\text { Operable vents - air velocity } \\
\text { control }\end{array}$ & $\begin{array}{l}\text { State change - } \\
\text { biochemical reaction }\end{array}$ \\
\hline $\begin{array}{l}\text { Users } \\
\text { Preference settings -manual } \\
\text { control }\end{array}$ & Direct control & Control panel-web application -mobile applications \\
\cline { 2 - 3 }
\end{tabular}

and ambient formats, alerting users when occupant actions would compromise energy optimization. For example, opening the louvres on a sunny day. So that, the building's users can gain awareness by time, and regulate their actions according to climate and energy load. Finally, both the building and the residents are in an ongoing, evolving conversation [6].

\subsubsection{Intelligent component}

The aim of an intelligent building component is to improve the buildings' system according to the outdoor climatic conditions, energy consumption, and users' comfort. Using building automation, and physically responsive features (Fig. 2) such as louvers, sunshades, operable windows and smart material assemblies.

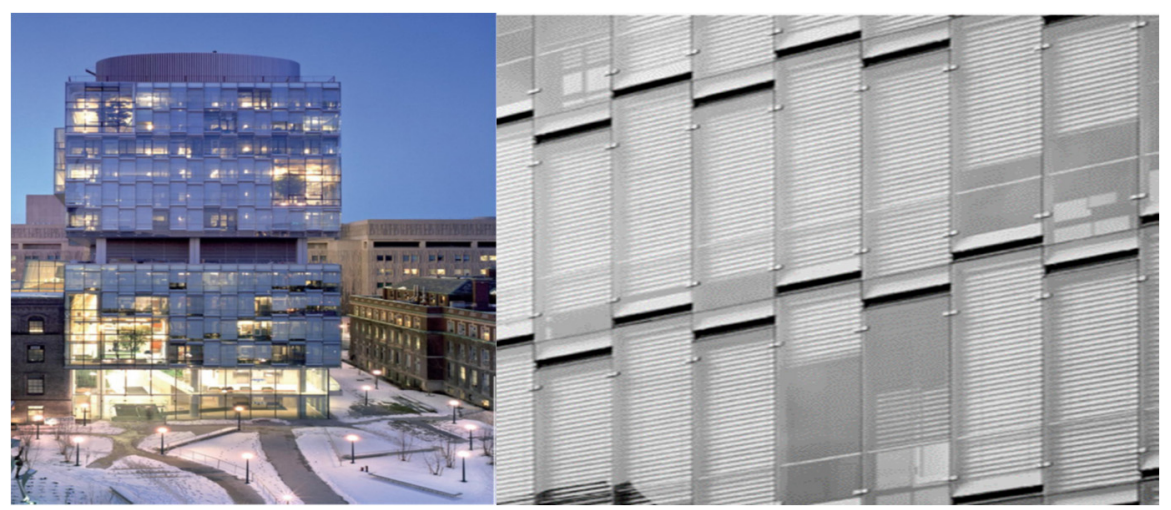

Figure 2: Intelligent double-skin façade system for the Terrence Donnelley Centre for Cellular and Bimolecular Science at the University of Toronto with integral automatic shading [6].

\subsubsection{Smart material}

"Smart materials" are described by Addington and Schodek as systems with "embedded technical functions" which provides specialized environmental responses, operating either through internal change in physical possessions or through external exchange of energy Smart materials have a number of characteristics that distinguish them from the known traditional materials as shown in Fig. 3 [8]. 


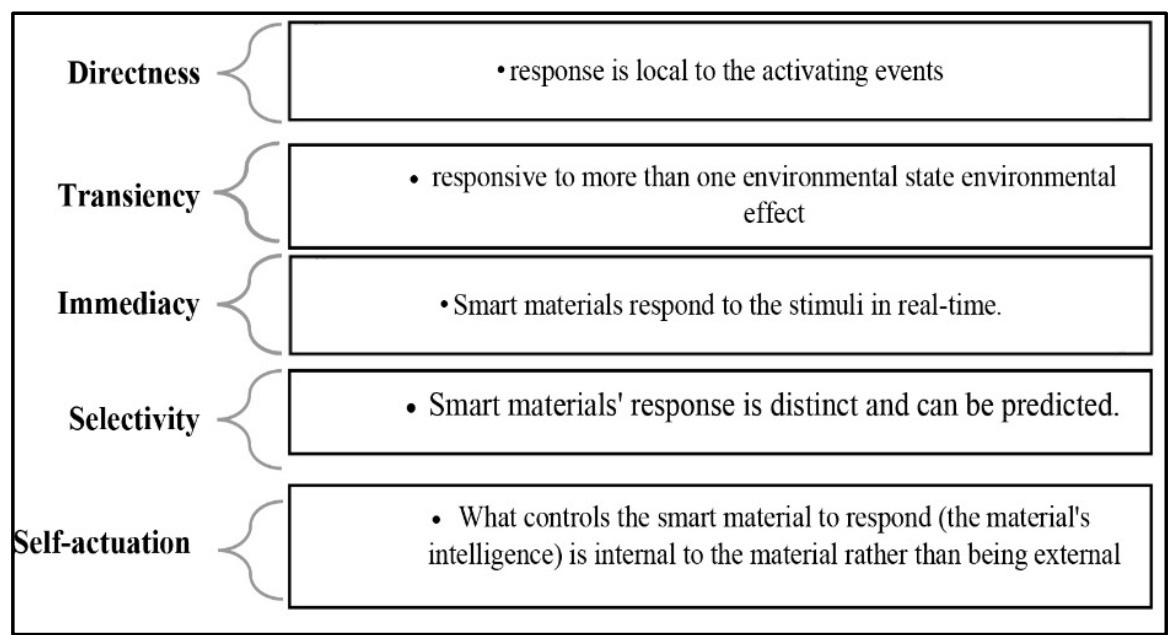

Figure 3: Characteristics of smart materials. (Source: [8] edited by author.)

Due to their integral characteristics, smart materials can play an important role in responsive envelopes. One of the most crucial features of smart materials is that they form responsive systems by themself. Through, there capability of transforming their materialistic features, and/or shape or exchanging energy without the need for complex electromechanical systems or additional energy supply [9].

A recent example of a responsive smart material installed in a completed building is media-TIC building, (Fig. 4) in Barcelona in 2011 designed by Cloud 9 architects and envelope specialists Vector Foiltec Ltd.

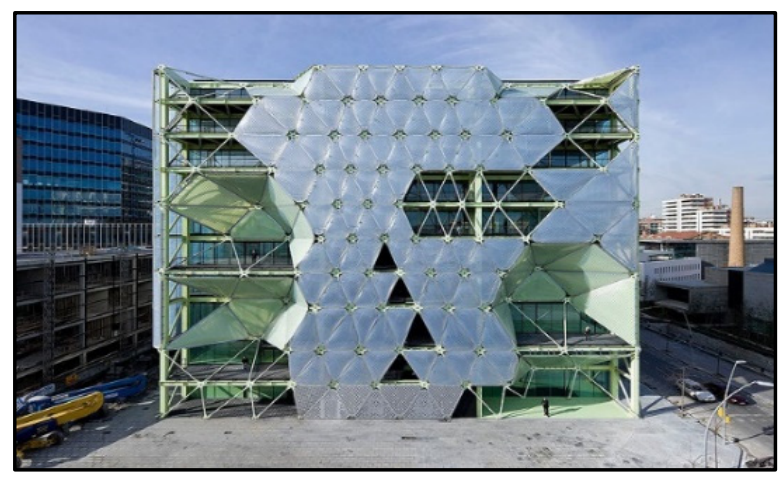

Figure 4: Smart envelope comprised of ETFE encased solar-activated lamella shades developed for the Media-TIC building in Barcelona [4].

The envelope is composed of a pillow cladding system made of ETFE (ethylene tetrafluoro ethylene), a transparent polymer sheeting that is ultralight and elastic while being extremely robust. EFTE is used as an alternative to glass and hard plastic in some new structures [4]. 
There are 106 EFTE membranes or pillows in total, which will gradually inflate or deflate based on the environmental condition (Fig. 5). Each "pillow" is regulated individually, with separate sensors detecting heat, temperature, and sun angle.

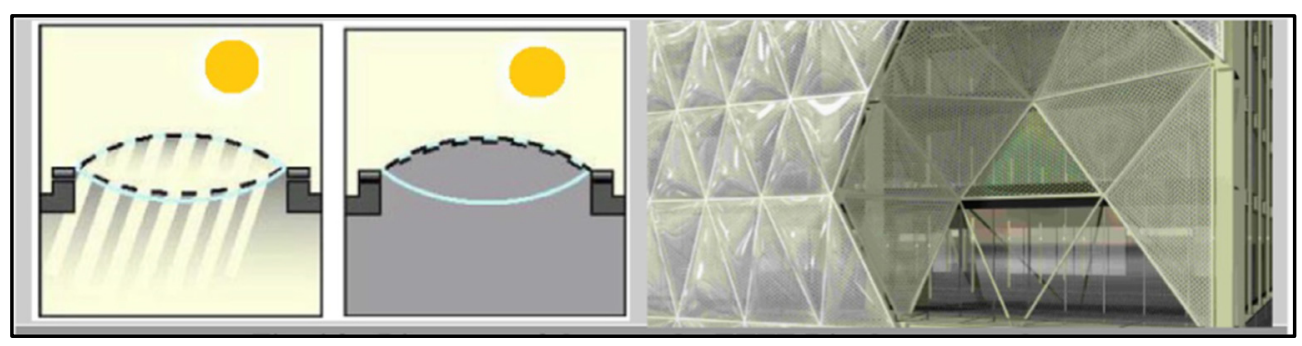

Figure 5: Diagrams of the way the ETFE diaphragm move in response to climatic conditions [4].

When compared to glass the use of ETFE material reduces energy consumption by $40 \%$, lowering the solar factor (SF) by four times, from 0.45 , as required by the Building Code, to 0.10 , and costs between 24 and $70 \%$ less to construct [4].

\section{NANOMATERIALS AND SMART MATERIALS}

An important aspect of sustainability in buildings is the efficient use of energy. Nanomaterials and nanotechnologies have a great potential for achieving high-performance energy-efficient buildings for a sustainable future. It is a revolutionary technique that deals with manipulating materials at the nanoscale, affecting their characterization, improving, or creating new properties of the product [10]. Nanotechnology can be employed in construction applications to provide one or more functions like air purification, selfcleaning, anti-soiling, energy generation, temperature regulation, solar radiation control, and fire prevention. The use of nanotechnology in architecture has not only been determined by energy efficiency and sustainability but also been involved in the architectural design process [11].

The availability of nanomaterials and nano-devices offer the possibility to produce smart materials. Nanomaterials add smartness to the materials using coating, like selfhealing, antimicrobial, anti-fouling, self-thermos regulating, etc. [7].

\section{ADAPTIVE NANO MATERIALS FOR ENERGY EFFICIENCY RESPONSIVE FAÇADES}

Nanotechnology has enormous potential in spatial deformation due to adjustable variance in material properties. The availability of nano microprocessors incorporated in smart materials allows them to transform shape in real-time in reaction to environmental changes. Consequently, respect the environmental concerns about sustainability. As a result, it will be an addition for architects to apply these materials to the building's façades to guarantee the optimum energy saving [7]. 
4.1 Adaptive nano material families and classification according to their input and output reactions

Adaptive materials have a range of values based on the switching parameter, or they have a "memory" for stored energy fluxes, such as phase transition materials. Because of the variety of these features, not all materials can be classified by the same set of properties. In Table 2 representative adaptive material families are categorized based on the dynamic behaviors or performance that can deliver in response to a specific trigger. This thorough material family classification is based on the input and output of the response, allowing for significant scoping in respective changes of application in facade systems. Although, this research will focus on phase change material and shape memory nanomaterial application for responsive façades [5].

Table 2: Material families and classification according to their input and output reactions. (Source: [5] edited by author.)

\begin{tabular}{|c|c|c|c|}
\hline $\begin{array}{l}\text { Reversible colour } \\
\text { opacity change }\end{array}$ & Shape changing & $\begin{array}{l}\text { Humidity } \\
\text { absorption }\end{array}$ & $\begin{array}{l}\text { Reversible heat flow } \\
\text { direction }\end{array}$ \\
\hline Electrochromic & Composites & \multirow{4}{*}{ Hydro gel } & \multirow{4}{*}{$\begin{array}{l}\text { Phase change } \\
\text { material (PCM) }\end{array}$} \\
\hline Thermochromic & Shape memory material & & \\
\hline Photochromic & Piezo electronic memory & & \\
\hline & Thermo bimetal & & \\
\hline
\end{tabular}

\section{PHASE CHANGE MATERIAL AND SHAPE MEMORY NANO MATERIALS}

Nanotechnology provides a novel concept for creating what could be termed as a "living facade." Using Stimulus responsive material (SRM) (Fig. 6). Such as, phase change material (PCM) which changed as a response to the rise of the temperature from the crystalline to the liquid state [12]. Or Smart materials supplied with (shape memory metal strips) that can remember their shape at the designed degree of temperature to be selfresponsive and adaptable according to the outdoor environmental changes. They can be used to cover the façades to detect heat and then change shape as the temperature changes. As a result, the change in these strips will cause the façades material to adapt to the change as well. Shape memory materials, like metal (SMA), polymers (SMP) or ceramics (SMC), can return to their original shape after removing the stimuli like the change of temperature, $\mathrm{pH}$-value, UV-light, electric or magnetic fields [7].

\subsection{Nano PCM (phase change material)}

PCM (phase change material) can be used to effectively regulate indoor room temperatures. It's also referred to as latent heat storage materials. The concept is like that of an ice cube in that it has a large thermal capacity and begins to change state to liquid at $0^{\circ} \mathrm{C}$, but the energy required for this transition is equivalent to that required to heat liquid water from $0^{\circ} \mathrm{C}$ to $80^{\circ} \mathrm{C}$. The same idea is used here with PCM.

Building temperature regulation require massive amounts of energy, both for heating and cooling. With the help of nanotechnology PCM is made up of microcapsules on a nanoscale, and its contents operate on absorbing heat; hence, energy consumption can be greatly reduced. Since PCM thermal storage is so large, it can absorb temperature fluctuations, allowing indoor spaces to stay colder for longer periods of time [14]. 


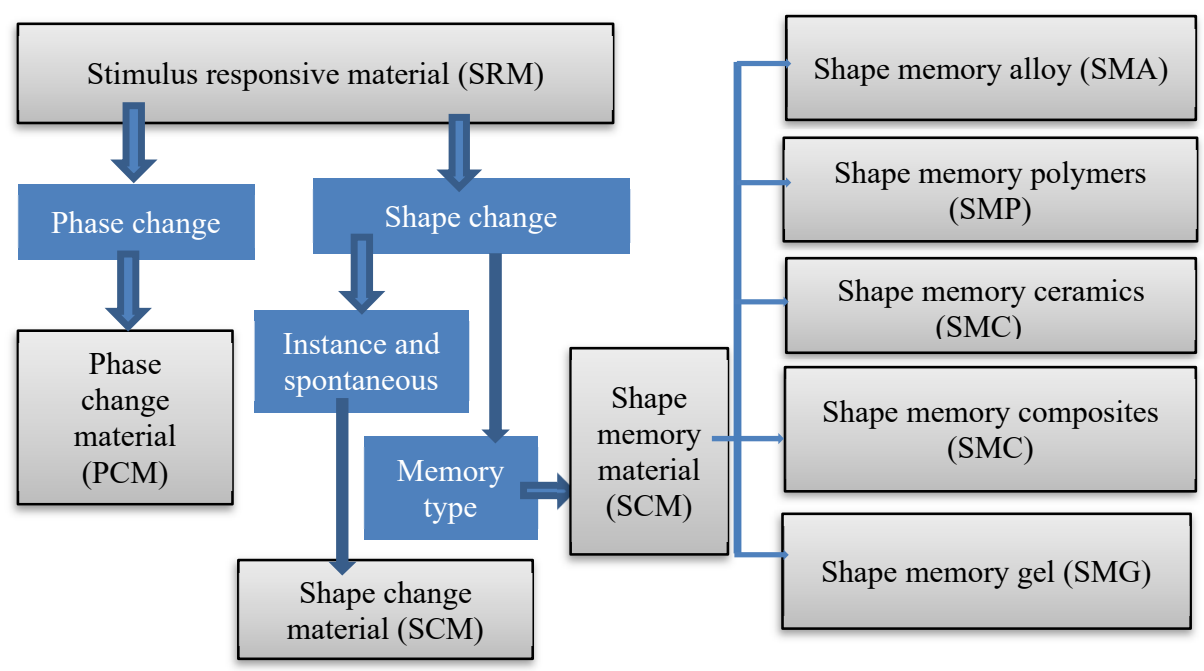

Figure 6: Phase change material and shape memory nano materials [13].

The inclusion of PCM on building elements has been assessed in façades as follow Fig. 7: window panels, dynamic shading systems, Trombe walls, concrete blocks, and cellulose insulation [14].
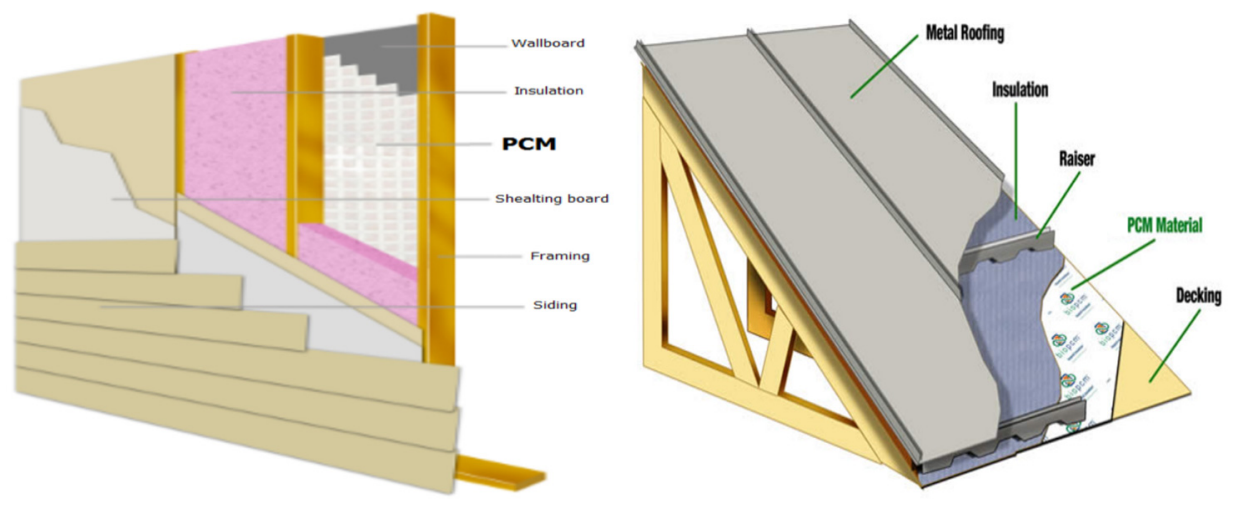

Figure 7: PCM current applications.

\subsubsection{PCM-incorporated transparent glazing}

Among building façades, approximately $50 \%$ of the energy is lost through windows, so more attention has been focused on energy efficient windows. The outer and inner insulating glazing units provide the passive solar mechanism of PCM glazing systems. The outer insulated glazing unit with suspended prismatic filter between the panes of glass reflects the higher angle sunlight back out while transmitting the low-angle sunlight into the inner unit (Fig. 8) [15]. 


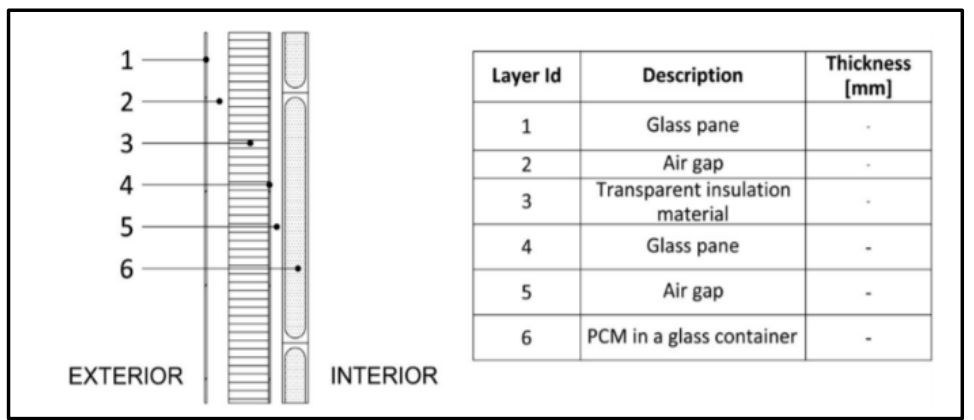

Figure 8: Layout of external PCM glazing system [15].

As a result, the summer sun is kept out of the building, while the lower angle winter sunlight is allowed to be captured by the PCM, as illustrated in Fig. 9. This potential is allowed by the phase transition between the liquid and solid states, allowing the glazing system's thermal inertia to be increased. The overall result of this process is a reduction in heat flow from outdoor to inside space during the daytime, which saves a significant amount of energy [15], [16].

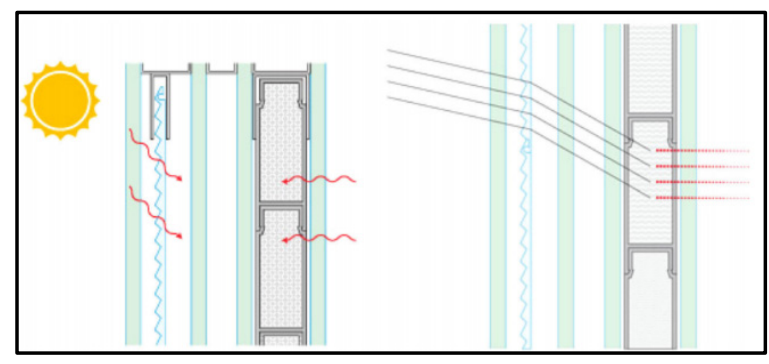

Figure 9: Fundamentals of operation of transparent PCM [15].

\subsection{Example of PCM application in a dynamic façade of University of Washington building}

\subsubsection{Project overview}

This project was designed to take full use of the naturally occurring natural climate variations that occur in the Pacific Northwest on a daily basis. Thus, the project designer used a phase change material to take advantage of temperature variations, allowing the material to disperse heat gathered during the day and avoid the need for traditional mechanical cooling [17].

\subsubsection{PCM integration with dynamic envelope system}

The design team worked with Phase Change Energy Solutions to identify the proper temperature and volume of phase change material. The Phase Change Energy Solutions material was installed in cavities above each level and the exterior solid walls to absorb heat from solar gain, electronics, and people. The damper system turns on mechanical 


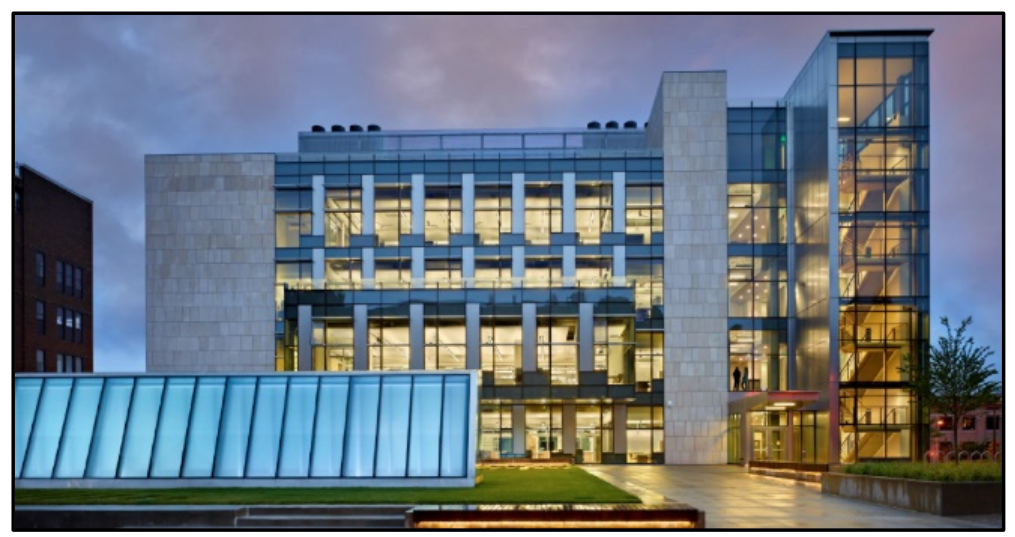

Figure 10: University of Washington building [17].

louvres that combine with ventilation fans at night. This mechanism sweeps cool outside air over the PCM, allowing it to release and exhaust heat collected during the day. This process allowed the PCM to recharge, allowing it to absorb the day's excess heat [17].

\subsubsection{Energy saving results}

This unique design concept is quite effective. HCAV energy consumption was reduced by $31 \%$. The building's occupants are satisfied, and the energy savings are projected to be $\$ 70,000$ per year [17].

\subsection{Shape memory alloys (SMA)}

Shape-memory alloys have several unique properties, including shape memory and super elasticity compared with standard metallic material's dissipation capacity. The usage of SMA in architecture, whether as a standalone dynamic system or as part of a larger system, has shown a significant increase in performance and energy savings [13].

For adaptive façades, SMA is used to manage solar gain, which provides a kinetic system that can move without the use of motors, electricity, or mechanical parts. So, enhancing the energy efficiency of buildings through changes in light, temperature, and air quality. The uses of SMA in architecture either as a dynamic system by itself or as a part of a bigger one has shown an important improvement in performance and energy consumption [18].

\subsubsection{Nickel-Titanium alloy (NITI)}

NITI because of its consistent mechanical performance, is the most reported SMA in responsive envelope systems using the non-diffusional phase transition protocol as an actuator (Fig. 11). NITI matrix was employed as an actuator by several dynamic surfaces focusing on the management of heat and light in buildings. The operation of these systems is based on prestressed springs or wires that attempt to restore their normal shape because of heat changes, which generate mechanical force in the operation [18].

As a resault of the mechanical force acquired by NITI phase transition, the use of NITI as wires and springs was reported and was used to panels skins illustrated in Fig. 12, dynamic indirect illumination and heat-gain control by shadowing were obtained [19]. 


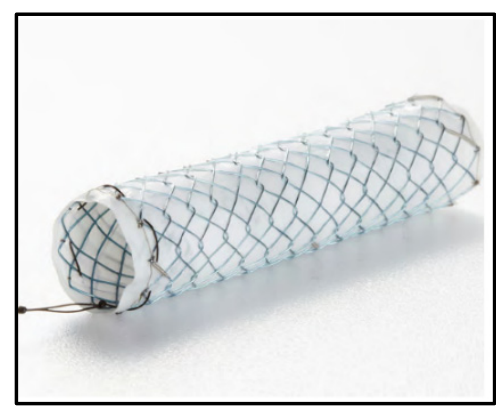

Figure 11: Nickel-titanium alloy (NITI) [5].

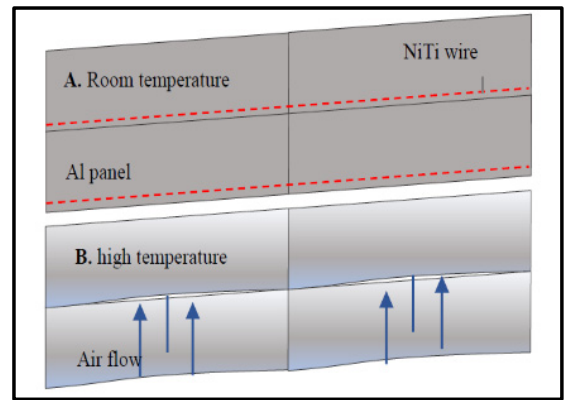

Figure 12: Kinetic facade actuated by NITI wires. A. Close module wire stressed. B. Open module wire contraction [13].

5.4 Example of Shape Memory Alloy - THERMAL BIMETAL, "BLOOM”, Los Angeles, California (USA), 2011 DO|SU Studio Architecture, Doris Kim Sung

A research installation titled "Bloom", designed by DO|SU studio architecture, was on exhibit at the materials and application gallery in Los Angeles without the need of an energy source or other mechanical parts, using a material having responsive potential (Fig. 13). The project functions as a solar tracking detector that detects time and temperature [5]. When the metal is cool, the surface appears as a solid object, but when the afternoon heat penetrates the metal, the panels of custom woven bimetal adjust and fan out to enable air movement and improve shadow potential.

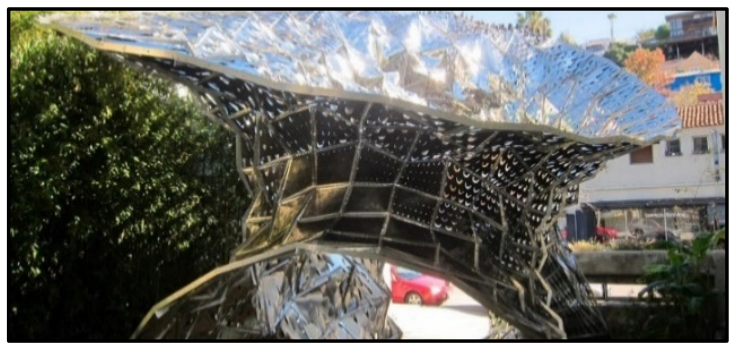

Figure 13: Thermal bimetal, "BLOOM" [20]. 
The towering shade structure is supported by a self-organizing cellular panel system made of laser cut custom fabricated thermo-bimetal alloys sheet metal, which tests the materials' ability to work as a responsive shell.

The design of the project explores the possibilities of a thermally responsive metal surface which reacts to both the change in temperature and direct solar radiation for energy saving [20].

\section{CONCLUSIONS}

Responsive building façades will play a crucial role in converting the world's energy usage into a more decentralized, sustainable, integrated and flexible system that guarantees sustainability and allows optimum use of all resources while at the same time enabling a healthy living and working atmosphere for inhabitants.

Additionally, nanotechnology provides new set of smart material and devices with responsive properties. So, designers and architects get a new material to deal with. Providing the optimum design solutions for sustainable energy efficiency responsive architectural façades.

As a result, architects will need to be knowledgeable about the properties of smart materials. Then, to use them as a preliminary step for an integrative design process and to push the boundaries of creativity in multi-functional sustainable complex patterns in architectural design.

All the materials that are mentioned above could provide energy efficiency, sustainability, high performance features and also aesthetic dynamics.

Furthermore, active materials for responsive building façades represent a highly promising sector of research and innovation that has the potential to transform the way we construct buildings in areas such as sustainable society and smart cities. However, largescale solutions, lower costs, and improved durability, notably with shape memory/responsive polymers SMP, must be developed further.

Finally, to provide optimal solutions, areas such as artificial intelligence, big data, and the internet of things are crucial to be integrated into responsive buildings envelops for the optimization of those materials, and systems within the cities.

\section{REFERENCES}

[1] Galloa, P. \& Romanoa, R., Adaptive façades, developed with innovative nanomaterials, for a sustainable architecture in the Mediterranean area. Procedia Engineering, 180, pp. 1274-1283, 2017.

[2] Taveres-Cachata, E., Grynninga, S., Thomsena, J. \& Selkowitzc, S., Responsive building envelope concepts in zero emission neighbourhoods and smart cities: A roadmap to implementation. Building and Environment, pp. 446-457, 2019.

[3] Romano, R., Aelenei, L., Aelenei, D. \& Enrico Sergio, M., What is an adaptive façade? Analysis of recent terms and definitions from an international perspective. Facade Design and Engineering, pp. 56-76, 2018.

[4] Samir, H. \& Shahin, M., Adaptive building envelopes of multi-storey buildings as an example of high-performance building skins. Alexandria Engineering Journal, pp. 345-352, 2019.

[5] Aelenei, L., Brzezicki, M., Knaack, U., Luible, A., Perino, M. \& Wellershoff, F., Adaptive Facade Network - Europe. TU Delft Open, 2015.

[6] Thun, G. \& Velikov, K., Responsive Building Envelopes: Characteristics and Evolving Paradigms, 2013. 
[7] Jalil, W.A., Smart textiles for the architectural façade. IOP Conference Series: Materials Science and Engineering 737. IOP Publishing, 2020.

[8] Addington, M. \& Schodek, D., Smart Materials and Technologies for the Architecture and Design Professions, Routledge, 2004.

[9] Markopoulou, A., Design Behaviour Programming the Material World for Responsive Architecture. Universidad Politécnica de Catalunya (UPC): Barcelona, 2018.

[10] Sev, A. \& Ezel, M., Nanotechnology innovations for the sustainable buildings of the future. International Journal of Civil, Architectural, Structural and Construction Engineering, pp. 858-868, 2014.

[11] Ibrahim, M.A., Hanafi, M.A. \& Omar, O.M., Nanoarchitecture and global warming. International Journal of Scientific \& Engineering Research, 2012.

[12] Youssef, M.M., Smart textiles as hybrid interactive materials a responsive behaviour towards transformable surfaces. International Design Journal, pp. 215-226, 2015.

[13] Villegas, J.E., Gutierrez, J.C.R. \& Colorado H.A., Active materials for adaptive building envelopes: A review. Journal of Materials and Environmental Science, pp. 988-1009, 2020.

[14] Casini, M., Smart Buildings: Advanced Materials and Nanotechnology to Improve Energy-Efficiency and Environmental Performance, Woodhead Publishing: Cambridge, 2016.

[15] Kalogirou, P., Fokaides, A., Angeliki, K. \& Soteris, A., Phase change materials (PCMs) integrated into transparent building elements: A review. Materials for Renewable and Sustainable Energy, pp. 1-13, 2015.

[16] Vigna, I., Bianco, L. \& Goia, F., Phase change materials in transparent building envelopes: A strengths, weakness, opportunities and threats (SWOT) analysis. Energies, 3, 2018.

[17] Phase Change Solutions, Phase Change Solutions, 2020. https://phasechange.com/ case-studies/university/. Accessed on: 10 Jul. 2021.

[18] Sun, L., Huang, W.M., Ding, Y. \& Zhao, C., Stimulus-responsive shape memory materials: A review. Materials \& Design, pp. 577-640, 2012.

[19] Khoo, C.K., Burry, J. \& Burry, M., Soft responsive kinetic system: An elastic transformable architectural skin for climatic and visual control, Proceedings of the 31st Annual Conference of the Association for Computer Aided Design in Architecture, ACADIA, 11: Integration through Computation, pp. 334-341, 2011.

[20] Furuto, A. Bloom/DO|SU Studio Architecture. ArchDaily, 12 Mar. 2012. https://www.archdaily.com/215280/bloom-dosu-studio-architecture. Accessed on: 15 Jun. 2021. 